\title{
SEMIÓTICA JURÍDICA COMO PARTE DA SEMIÓTICA GERAL: INTERTEXTUALIDADES E INFLUÊNCIAS
}

\author{
Vinícius Wagner de Sousa Maia*
}

\begin{abstract}
Resumo
Este trabalho parte da hipótese de que o direito pode ser investigado pela abordagem semiótica, mas para isso é preciso inicialmente compreender que existem diferentes teorias e modelos explicativos semióticos, o que é tratado no tópico $1.1 \mathrm{em}$ sua dimensão conceitual. Adiante, no tópico 1.2, aprofunda-se a análise a partir dos desdobramentos teóricos de Saussure, Jakobson, Peirce e Greimas. No tópico 1.3 apresenta-se uma análise desenvolvida por Greimas e outros investigadores envolvendo A construção de objetos semióticos: análise semiótica de um discurso jurídico: a lei comercial sobre as sociedades e os grupos de sociedades. A conclusão confirma a hipótese.
\end{abstract}

Palavras-chave: Semiótica; Direito; Signo; Linguagem; Metalinguagem.

\section{LEGAL SEMIOTICS AS PART OF GENERAL SEMIOTICS: INTERTEXTUALITIES AND INFLUENCES}

\begin{abstract}
This work starts from the hypothesis that the law can be investigated by the semiotic approach, but for that it is necessary to initially understand that there are different theories and semiotic explanatory models, which is treated in topic 1.1 in its conceptual dimension. Ahead, in topic 1.2, the analysis is deepened based on the theoretical developments of Saussure, Jakobson, Peirce and Greimas. Topic 1.3 presents an analysis developed by Greimas and other researchers involving "The construction of semiotic objects: semiotic analysis of a legal discourse: the commercial law on societies and groups of societies". The conclusion confirms the hypothesis.
\end{abstract}

Keywords: Semiotics; Right; Sign; Language; Metalanguage.

\section{INTRODUÇÃO}

O direito analisado a partir de teorias semióticas, apresenta-se como linguagem objeto. Analisar o direito a partir de uma abordagem semiótica exige compreensão dos

\footnotetext{
* Bacharel em Direito, Especialista em Políticas Públicas e em Ciências Criminais pela Universidade Federal de Goiás (UFG), Mestre em Direito, Relações Internacionais e Desenvolvimento e Doutor em Ciências da Religião pela Pontifícia Universidade Católica de Goiás (PUC/GO). E-mail: vinicius.w.s.maia@gmail.com.
} 
conceitos, teorias e modelos explicativos semióticos a fim de que se possa realizar a correta utilização das teorias. Sendo assim, os objetivos deste trabalho consistem na possibilidade de utilização de teorias semióticas para investigar o direito, e havendo possibilidade, qual o modo de fazê-lo preservando a cientificidade da investigação. As metodologias utilizadas consistem na apresentação de diferentes conceitos, a partir dos conceitos apresentam-se diferentes modelos teóricos, em seguida verifica-se a aplicação de um modelo teórico semiótico a uma lei específica. Segue-se a crítica. O desenvolvimento do trabalho compreende um Capítulo subdividido em três tópicos. $\mathrm{Na}$ parte introdutória do capítulo procura-se compreender a problemática em sentido geral, no âmbito da ciência. O tópico 1.1 apresenta conceitos de diferentes atores, os quais levam a diferentes modelos teóricos, o que será abordado no tópico 1.2. Neste tópico aprofunda-se a análise a partir dos desdobramentos teóricos de Saussure, Jakobson, Peirce e Greimas. No tópico 1.3 apresenta-se uma análise desenvolvida por Greimas e outros investigadores envolvendo A construção de objetos semióticos: análise semiótica de um discurso jurídico: a lei comercial sobre as sociedades e os grupos de sociedades. Conclui-se com a confirmação da hipótese.

\section{O QUE É SEMIÓTICA E COMO SE DÁ}

A semiótica pressupõe diversas capacidades humanas, como a lógica, a razão, a simbólica, a linguística, a sensiência, entre outras, que se interrelacionam dialeticamente. Esse emaranhado complexo de capacidades habilita as pessoas a criar, produzir, organizar e sistematizar símbolos, que num sentido bastante geral refere-se à dimensão semiótica.

A semiótica trata de uma capacidade humana geral, encontrada em quase todas as pessoas, em todos os tempos e espaços. A ausência dessa capacidade pode estar associada a aspectos biológicos, cognitivos, disfunções da linguagem, entre outros, que incapacitam a pessoa a realizar atos semióticos.

As pessoas podem efetuar diversas atividades semióticas corretamente (por exemplo, analisar um texto semioticamente) sem, no entanto, formularem explicitamente as reflexões, as críticas ou as regras dessa atividade. Ao formularem as reflexões, as críticas e as regras, inicia-se a abordagem científica. 
Uma vez que a semiótica não é apenas a atividade simbólica, mas também reflexão sobre os princípios que regem a própria atividade simbólica, esta só aparecerá quando já existir um corpo considerável de práticas semióticas.

Nas ciências que seguem a lógica dedutiva, os princípios fundamentais não são problematizados, apesar de serem problematizáveis. São aceitos apoditicamente. Eventual problematização dos conceitos, definições, regras, leis, vai ocorrer no âmbito da filosofia. Dessa maneira, a própria exposição da matéria no âmbito das obras literárias sobre o assunto é feita com a apresentação de conceitos e definições seguindo-se os aspectos relacionais, associativos, de exclusão, refutação, inferências.

As matérias semióticas podem ser estudadas dedutivamente, porém, a experiência semiótica se dá no âmbito da pragmática, o que exige rigor demonstrativo, levando em conta seu caráter empírico. A semiótica trata a linguagem transitando entre o sintático, o semântico e o pragmático. Morris (1976), em seus Fundamentos da teoria dos signos desenvolve um modelo explicativo tratando destes elementos.

A semantização e a pragmatização estão diretamente relacionadas com o uso da linguagem semiótica, sendo as denotações referidas a experiências históricas no tempo e no espaço e a pragmática referida aos interpretantes e intérpretes. Não é possível, porém, prescindir da dimensão indutiva, pois a semiótica envolve a experiência viva de interlocutores historicamente situados, ainda que se possa focar o aspecto sêmio-linguístico.

As ciências podem compreender objetos que preferem aspectos sintáticos, semânticos ou pragmáticos. Quanto mais tendem à logica-matemática, mais sintáticas são. Havendo maior foco no aspecto semântico, volta-se a atenção para as denotações. Sendo pragmático o foco, privilegiam-se os interpretantes, intérpretes, sujeitos e atores, podendo-se ampliar o foco para aspectos exteriores como tradições, memórias, histórias e lembranças. O aspecto sintático assegura o rigor lógico das demonstrações em qualquer ciência. $\mathrm{O}$ aspecto semântico assegura o rigor denotativo das demonstrações. O aspecto pragmático assegura o rigor demonstrativo na comunidade de linguagem. A semiótica transita por todas essas dimensões.

Definições e conceitos precisam ser demonstrados ou reconhecidos e aceitos, a depender de sua apoditicidade ou possibilidade de problematização. Um livro sobre semiótica, por exemplo, pode ser escrito com apresentação dos conceitos e definições, regras de formação de proposições, enunciados e sentenças, explicação das regras de inferência, leis 
que governam as relações, associações, exclusões, inferências ou seja, explica quais são os elementos, o que é o conjunto, como se relacionam os elementos, o que caracteriza o conjunto. Acrescente-se a isso as questões propriamente pragmáticas, o que remetem às práticas indutivas.

Ao lado das questões propriamente semióticas, que integram o conjunto Semiótica, também podem ser problematizados aspectos como sua linguagem, seus limites, suas possibilidades o que será tratado no âmbito da epistemologia, enquanto metaciência.

Costuma-se tratar por corpus o conjunto de escritos sobre determinado assunto. Assim, o corpus da semiótica compreende tudo que se tenha produzido a seu respeito.

Qualquer ciência utilizará em seu desenvolvimento: linguagens, explicitará de forma lógica os argumentos, demonstrações, comprovações, elegerá métodos, técnicas, metodologias, formas de nominar, explicar, observar (as regularidades, irregularidades, regras, exceções, a particularidades, generalidades, universalidades, hierarquias, causalidades), elaborar classificações, ordenar, criar novas linguagens ou formas lógicas adequados para tratar do objeto ou utilizar as linguagens e formas lógicas existentes. No caso da semiótica, se farão presentes os aspectos sintáticos, semânticos e pragmáticos tendo os signos e símbolos por elementos privilegiados e eixos organizadores dos discursos.

\title{
1.1 CONCEITO, CONJUNTO, DADOS E ELEMENTOS
}

A respeito do conceito, iniciando pelos clássicos fundamentais, Saussure explica:

\begin{abstract}
A língua é um sistema de signos que exprimem ideias, e é comparável, por isso, à escrita, ao alfabeto dos surdos-mudos, aos ritos simbólicos, às formas de polidez, aos sinais militares etc., etc. Ela é apenas o principal desses sistemas. Pode-se, então, conceber uma ciência que estude a vida dos signos no seio da vida social; ela constituiria uma parte da Psicologia social e, por conseguinte, da Psicologia geral; chamá-la-emos de Semiologia (do grego semeion, "signo"). Ela nos ensinará em que consistem os signos, que leis os rege. Como tal ciência não existe ainda, não se pode dizer o que será; ela tem o direto, porém, a existência; seu lugar está determinado de antemão. A linguística não é senão uma parte dessa ciência geral; as leis que a Semiologia descobrir serão aplicáveis à Linguística e esta se achará dessarte vinculada a um domínio bem definido no conjunto dos fatos humanos (SAUSSURE, 2006, p. 24).
\end{abstract}

Peirce, que identifica lógica e semiótica, por sua vez, conceitua:

A lógica é a ciência das leis necessárias gerais dos Signos e, especialmente, dos Símbolos. Como tal, tem três departamentos. Lógica obsistente, lógica em sentido 
estrito, ou Lógica Crítica, é a teoria das condições gerais da referência dos Símbolos e outros Signos aos seus Objetos manifestos, ou seja, é a teoria das condições de verdade. Lógica Originaliana, ou Gramática Especulativa, é a doutrina das condições gerais dos símbolos e outros signos que têm o caráter significante. É deste departamento da lógica geral que nós estamos agora ocupando. Lógica Transuasional, que denomino de Retórica Especulativa é, metodologia ou melhor metodêutica. É a doutrina das condições gerais de referência a Símbolos e outros Signos aos Interpretantes que pretendem determinar (PEIRCE, 2008, p. 29).

\title{
Bakhtin (Volóchinov) em sua obra Marxismo e filosofia da linguagem explica:
}

\begin{abstract}
Antes de mais nada, as próprias bases da ciência marxista da criação ideológica, isto é, os fundamentos dos estudos sobre a ciência, a literatura, a religião, a moral etc. estão ligados de modo mais estreito aos problemas da filosofia da linguagem. Qualquer produto ideológico é não apenas uma parte da realidade natural e social seja ele um corpo físico, um instrumento de produção ou um produto de consumo mas também, ao contrário desses fenômenos, reflete e refrata outra realidade que se encontra fora dos seus limites. Tudo que é ideológico possui uma significação: ele representa e substitui algo encontrado fora dele, ou seja, ele é um signo. Onde não há signo também não há ideologia

[...]

além dos fenômenos da natureza, dos objetos tecnológicos e dos produtos de consumo, existe um mundo particular: o mundo dos signos (VOLÓCHINOV, 2018, p. 91-93).
\end{abstract}

Benveniste, ao diferenciar os níveis semiótico e semântico o faz como segue:

O signo saussureano é na verdade a unidade semiótica, quer dizer, a unidade dotada de sentido. É reconhecido o que tem sentido; todas as palavras que são encontradas num texto francês, para quem domina esta língua, têm um sentido. [...] O nível semiótico é isto: ser reconhecido como tendo ou não um sentido. Isto se define por sim, não. [...] A "semântica" é o sentido resultante do encadeamento, da apropriação pela circunstância e da adaptação dos diferentes signos entre eles. Isto é absolutamente imprevisível. É a abertura para o mundo. Enquanto o semiótico é o sentido fechado sobre si mesmo e contido de algum modo em si (BENVENISTE, 1989, p. 21).

O autor explica mais, que o valor semiótico está presente em diferentes aspectos da cultura, compreendendo a arte, as tradições etc.

Greimas \& Courtés ao tratarem da linguística a relacionam com a semiótica do seguinte modo:

\begin{abstract}
A linguística pode ser definida como um estado científico da linguagem e das línguas naturais, estando a reflexão teórica sobre a linguagem (que se integra na teoria semiótica, mais geral) concentrada na natureza, funcionamento e procedimentos de descrição das línguas naturais e alimentando-se, ao mesmo tempo, dos resultados da análise dessas línguas (GREIMAS e COURTÉS, 2008, p. 261).
\end{abstract}

Eco, por sua vez, ao tratar do objetivo de sua obra Semiótica o faz como segue: 
O objetivo deste livro é explorar as possibilidades teóricas e as funções sociais de um estudo unificado de todo e qualquer fenômeno de significação e/ou comunicação.

Esse estudo assume a forma de uma TEORIA SEMIÓTICA GERAL capaz de explicar qualquer caso da FUNÇÃO SÍGNICA em termos de SISTEMAS subjacentes correlatos de um ou mais CÓDIGOS.

Um projeto de semiótica geral compreende uma TEORIA DOS CÓDIGOS e uma TEORIA DA PRODUÇÃO SÍGNICA; a segunda teoria leva em consideração um grupo muito vasto de fenômenos, tais como o uso natural das diversas "linguagens", a evolução e a transformação dos códigos, a comunicação estética, os vários tipos de interação comunicativa, o uso dos signos para mencionar coisas e estados do mundo, e assim por diante (ECO, 2009, p. 2).

Kristeva, a seu turno, ao tratar da semiótica o faz como segue:

En un movimiento decisivo de auto-análisis, el discurso (científico) vuelve en la actualidad a los lenguajes para extraer sus (y de él) modelos.

Dicho de outro modo, ya que la práctica (social: es decir la economía, las costumbres, "el arte, etc.) es cosiderada como un sistema significativo "estructurado como lenguaje”, toda práctica puede ser científicamente estudiada en tanto que modelo secundario con relación a la lengua natural, modelada sobre esa lengua y modelándola.

Es justamente en ese lugar donde se articula la semiótica, o, mas bien, actualmente, se buscal (KRISTEVA, 1981, p. 35).

Ao tratar sobre semiótica, Nöth a conceitua como segue: “[...] semiótica é a ciência dos signos e dos processos significativos (semiose) na natureza e na cultura" (NÖTH, 1995, p. 17). Esclarece, o autor, adiante, que a definição não é aceita por todos que estudam semiótica, preferindo alguns uma definição mais específica e restritiva, enquanto outros exigem que a semiótica se ocupe apenas da comunicação humana. A escola de Greimas até se recusa a definir semiótica como uma teoria de signos, postulando, ao contrário, defini-la apenas como uma teoria da significação. Conforme explicação do autor a semiótica, tratando da ciência dos signos e dos processos significativos, não se restringe ao campo da linguagem, de tal forma que pode haver semiótica do cinema, da arte, da moda, da cultura etc.

Corroborando tal assertiva, podemos encontrar a obra de Lotman, La semiosfera: semiótica de la cultura y del texto ( (1996). Lotman explica que a semiótica atual está passando por um processo de revisão de alguns conceitos básicos, sabendo-se que há duas tradições principais. A primeira que parte de Peirce e Morris, tratando do conceito do signo

1 Tradução livre: Em um movimento decisivo de autoanálise, o discurso (científico) volta na atualidade às linguagens para extrair seus (e dele) modelos. Dito de outro movo, já que a prática (social: quer dizer, a economia, os costumes, a arte etc.) e considerada como um sistema significativo "estruturado como linguagem", Toda prática pode ser estudada cientificamente como um modelo secundário em relação à linguagem natural, modelado nessa linguagem e modelando-a. É justamente nesse lugar que a semiótica se articula, ou melhor, atualmente, é buscada. 
como elemento primário de todo sistema semiótico. A segunda, fundada nos ensinamentos de Saussure e da Escola de Praga, toma semiótica como fundamento da antinomia entre a língua e a fala (LOTMAN, 1996, p. 10).

Em outra obra escrita em conjunto com Santaella, Nöth apresenta o seguinte conceito:

\begin{abstract}
Numa primeira definição, podemos dizer que a semiótica é a ciência dos sistemas e dos processos sígnicos na cultura e na natureza. Ela estuda as formas, os tipos, os sistemas de signos e os efeitos do uso dos signos, sinais, indícios, sintomas ou símbolos. Os processos em que os signos desenvolvem o seu potencial são processos de significação, comunicação e intepretação (NÖTH e SANTAELLA, 2017, p. 7).
\end{abstract}

No sentido de que a abrangência semiótica pode variar explica Klinkenberg:

La semiótica puede, pues, definirse como la ciencia de los signos.

Existen diferentes formas de "lenguaje", pero todas están fundadas sobre signos. La disciplina que cubre ese conjunto es la semiótica.

Al conferir a la semiótica un campo de aplicación tan vasto, nos alejamos progresivamente de la idea según la cual esta disciplina tendría un objeto exclusivo. Porque si se reflexiona bien sobre esto, el signo está en todas partes: se halla en el arte de la veterinaria, en los códigos secretos, la meteorología y la caza con galgos. No es, entonces, tanto un objeto particular lo que constituye el terreno de la semiótica, cuanto el punto de vista particular que ella toma sobre una multitud de $\operatorname{objetos}^{2}[\ldots]$ (KLINKENBERG, 2006, p. 33).

Por esta razão, quando se vai tratar de alguma questão semiótica, é importante especificar a abrangência, o objeto, o método, e sendo possível a escola ou autor que se tomará por referência. Assim o faz Barros em sua obra Teoria semiótica do texto ao especificar:

A intenção deste livro é apresentar, de forma sucinta e simples, os fundamentos da
teoria semiótica. Por teoria semiótica está-se entendendo a teoria desenvolvida por
A. J. Greimas e pelo Grupo de Investigações Sêmio-linguísticas da Escola de Altos
Estudos em Ciências Sociais. Existem outras teorias semióticas, também bastante
conhecidas, como a de Charles Peirce e a da Escola de Tartu. Por razões diversas,
entre as quais a de exiguidade de espaço e a de tipo de publicação, não se farão
comparações entre as diferentes propostas e, muito menos, apreciações do mérito e
das vantagens indiscutíveis de cada uma delas. A opção pela semiótica greimasiana
deve-se a motivos vários, alguns mesmo de ordem pessoal, e merece referência o

${ }^{2}$ Tradução livre: A semiótica pode, portanto, ser definida como a ciência dos signos. Existem diferentes formas de "linguagem", mas todas são baseadas em signos. A disciplina que abrange esse conjunto é a semiótica. Ao dar à semiótica um campo de aplicação tão vasto, progressivamente nos afastamos da ideia de que essa disciplina teria um objeto exclusivo. Porque se você refletir bem sobre isso, o sinal está em todo lugar: está na arte da medicina veterinária, nos códigos secretos, na meteorologia e na caça com galgos. Não é, então, tanto um objeto particular que constitui o terreno da semiótica, mas o ponto de vista particular que assume uma multidão de objetos. 
caráter de teoria do texto que assume a semiótica escolhida para esta apresentação (BARROS, 2005).

E após ter apresentado referidos motivos, a autora trata da semiótica no âmbito textual como segue: “[...] a semiótica tem por objeto o texto, ou melhor, procura descrever e explicar o que o texto diz, e como ele faz para dizer o que diz" (BARROS, 2005, p. 11).

É de se notar, pois, que eventuais pesquisas ou investigações semióticas partem de escolas científicas ou teóricas como comunidades de linguagem envolvendo grupos de pesquisadores que se reúnem, cada qual desenvolvendo investigações e estudos sobre temas específicos da semiótica. Há também gerações de pesquisadores e investigadores que dedicam suas vidas a referidos estudos e investigações. Esses aspectos são externos aos estudos semióticos. Aspectos internos dizem respeito às investigações, estudos e pesquisas propriamente semióticos. Neste trabalho consideramos apenas os aspectos internos.

Sendo Saussure e Peirce os fundadores da semiótica em seu sentido científico, são referências básicas e fundamentais para quem pretenda desenvolver qualquer análise sobre o tema. Outros autores como Roland Barthes (1915-1980), Algirdas Julius Greimas (19171992), Roman Jakobson (1896-1982), Louis Hjelmslev (1899-1965), Umberto Eco (19322016), Émile Benveniste (1902-1976), desenvolvem reflexões, estudos e investigações que ampliam e aprofundam as questões formuladas pelos fundadores.

Apresentados alguns conceitos de semiótica, tratemos agora dos elementos e conjuntos, no sentido interno. Elementos são dados compreendidos no conjunto que se rotula como Semiótica. Enquanto o conjunto pode abarcar o corpus semiótico, ou seja, tudo que já se produziu a respeito do assunto, em um sentido mais restrito pode compreender a totalidade sistêmica que ordena os elementos semióticos em cada teoria ou modelo explicativo elaborado por cada autor ou escola. O conjunto pode compreender, pois, a totalidade das investigações, pesquisas e estudos sobre semiótica em todos os tempos e espaços, a totalidade produzida por uma escola teórica, a totalidade produzida por um pesquisador em particular. Seja qual for a dimensão do conjunto, será integrado por elementos.

Individualmente considerados e sem alusão a qualquer conjunto ou modelo explicativo os elementos são privados de sentido, ainda que possam possuir significado. Pode ocorrer de não possuírem sequer significado se adotarmos um modelo teórico estruturalista que se caracteriza justamente pelo fato de os significados serem identificados pelas diferenças que possuem em relação a outros significados. Sendo assim, parece ser uma condição 
fundante da semiótica a relação que os elementos possuem entre si, dentro das estruturas e de determinadas teorias ou modelos explicativos. A compreensão das relações entre elementos e conjuntos é que torna possível compreender a semiótica em sua dimensão significativa.

A sintaxe pretende apresentar os elementos explicitando suas relações entre si. A sintaxe mostra o arranjo dos elementos em suas relações estruturais, formais, lógicas, matemáticas. A semântica pretende apresentar os elementos explicitando suas relações com os denotatum, que podem ser objetos lógicos, matemáticos, conceituais ou empíricos. A pragmática pretende apresentar os elementos explicitando suas relações com os intérpretes e interpretantes. Pode-se tratar sintaxe, semântica e pragmática como conjuntos cujos elemento se relacionam segundo regras próprias a cada qual.

Saussure elegeu a língua como objeto de suas investigações.

O objeto de nosso estudo é, pois, o produto social depositado no cérebro de cada um, isto e, a língua. Mas tal produto difere de acordo com os grupos linguísticos: o que nos é dado são as línguas. O linguista está obrigado a conhecer o maior número possível delas para tirar, por observação e comparação, o que nelas exista de universal (SAUSSURE, 2006, p. 33).

Ao fazê-lo estabeleceu os limites de sua análise e investigação.

\subsection{MODELOS TEÓRICOS}

Feita esta eleição, pôde então Saussure dispor sobre a natureza do signo e as duas leis que regem sua teoria. Ao tratar do signo, escreveu:

\footnotetext{
O signo linguístico une não uma coisa e uma palavra, mas um conceito e uma imagem acústica. Esta não é o som material, coisa puramente física, mas a impressão (empreinte) psíquica desse som, a representação que dele nos dá o testemunho de nossos sentidos; tal imagem é sensorial e, se chegamos a chama-la de "material”, é somente neste sentido, e por oposição ao outro termo da associação, o conceito, geralmente mais abstrato (SAUSSURE, 2006, p. 80).
}

Saussure excluiu de sua pesquisa tudo que dizia respeito à fala, parole, restringindo, pois, sua investigação à língua. Fez isso tendo em conta que seu modelo teórico procurava focar a estrutura da linguagem em seus aspectos homogêneos e duradouros. À totalidade das pesquisas, estudos e investigações sobre o signo, Saussure chamou de semiologia, termo que posteriormente foi substituído por semiótica. A partir da conceituação o autor elaborou uma 
análise densa apresentando os princípios fundamentais de sua teoria, arbitrariedade do signo e caráter linear do significante, seguindo investigações sobre língua e fala, elementos internos e externos, linguística sincrônica e diacrônica, valor linguístico, sintagma e paradigma, linguística geográfica entre outros temas. Em Saussure, pois, o conjunto de todos os elementos em suas interrelações e explicações teórica consiste na semiologia.

Jakobson, ao refletir a influência de Saussure na delimitação do escopo de investigação da semiótica esclarece:

A lógica simbólica não tem deixado de lembrar-nos que as "significações
linguísticas", constituídas pelo sistema das relações analíticas de uma expressão com
outras expressões, não pressupõe a presença das coisas. Os linguistas, ao contrário,
fizeram o impossível para excluir a significação, e todo recurso à significação, da
linguística (JAKOBSON, 2010, p. 40).

Adiante o autor apresenta uma crítica, sugerindo a incorporação das significações linguísticas à ciência da linguagem. E avançando no desenvolvimento de sua teoria, apresenta dois esquemas que sintetizam os elementos de sua teoria comunicativa. O primeiro sintetiza os elementos da comunicação verbal:

\section{CONTEXTO}

MENSAGEM

REMETENTE

DESTINATÁRIO

CONTATO

CÓDIGO

Figura 1 - Elementos da comunicação verbal

Fonte: JAKOBSON, 2010, p. 157.

Mais à frente, ao tratar das funções básicas da comunicação verbal, o autor apresenta o seguinte esquema: 
EMOTIVA

\section{REFERENCIAL}

POÉTICA

FÁTICA

\section{METALINGUÍSTICA}

Figura 2 - Funções básicas da comunicação verbal

Fonte: JAKOBSON, 2010, p. 165.

Peirce, a seu turno, promoveu a seguinte análise:

Os signos são divisíveis conforme três tricotomias; a primeira, conforme o signo em si mesmo for uma mera qualidade, um existente concreto ou uma lei geral; a segunda, conforme a relação do signo para com seu objeto consistir no fato de o signo ter algum caráter em si mesmo, ou manter alguma relação existencial com esse objeto ou em relação com um interpretante; a terceira, conforme seu interpretante representá-lo como um signo de possibilidade ou como um signo de fato ou como um signo de razão (PEIRCE, 2008, p. 51).

O autor apresentou ainda duas outras tricotomias: ícone, índice e símbolo; rema, dicente e argumento. A partir dessas tricotomias, o autor elaborou um quadro teórico a partir do qual os elementos de sua semiótica podem responder à análise pretendida. À totalidade das investigações, o autor chama semiótica.

Cada um dos autores clássicos apresenta modelos explicativos que seguem ou derivam dos conceitos, derivando-se destes os demais elementos do modelo explicativo. Partindo da noção de estatuto semiótico social do indivíduo, Greimas chama de socioleto um:

[...] certo número de "linguagens" especializadas que o fazem participar, não de grupos sociais propriamente ditos, mas de "comuidades de linguagem" restritas, de grupos semióticos caracterizados pela competência que possuem em comum os indivíduos que dele fazem parte para emitir e receber certo tipo de discurso" (GREIMAS, 1981, p. 42).

Esclarece ainda, o autor, que:

[...] do ponto de vista semiótico, certo tipo de diferenciação social define-se não a partir de grupos sociais constituídos por meio de práticas sócio-econômicas comuns, mas levando em conta uma tipologia dos universos semânticos e dos discursos socializados, já que um único e mesmo indivídio pode participar de vários grupos 
semióticos e assumir tantos papéis sócio-semióticos quantos são os grupos em que se acha integrado (GREIMAS, 1981, p. 42-43) (Os itálicos são do original).

Greimas tem o cuidado de distinguir a participação na comunidade de linguagem da participação em grupos socio-econômicos, para deixar claro que um grupo sócio-econômico é apenas uma das formas de agrupamento entre pessoas. Um indivíduo pode participar de várias comunidades de linguagem, assumindo diferentes papeis sócio-semióticos. O socioleto difere do idioleto que é a forma de uma língua peculiar a um indivíduo. Difere, ainda, do dialeto, identificado por variações linguísticas diferenciadas no espaço. À totalidade teórica de seu modelo explicativo o autor chama de semiótica.

Quando o fenômeno coloca em contato diferentes línguas, emergem outros processos necessários à interlocução, tais como a tradução e a decodificação. Quando são transbordadas as barreiras dos estudos da linguagem em suas dimensões histórica ou sistemática, para alcançar as dinâmicas sociais, seja no universo da sociologia da linguagem, seja no da sociolinguística, os contextos em que se dão os diálogos assumem igual importância ao que se confere aos fatos linguísticos.

\subsection{SEMIÓTICA JURÍDICA COMO PARTE DA SEMIÓTICA GERAL}

Investigações sobre a semiótica, tendo o signo e o símbolo por eixos organizadores, podem compreender também aspectos dialógicos, enunciativos, comunicativos, ideológicos, entre outros. Há um estudo específico que relaciona semiótica e discurso jurídico em Greimas (1981, p. 69-114). Trata-se de um estudo sobre A construção de objetos semióticos: análise semiótica de um discurso jurídico: a lei comercial sobre as sociedades e os grupos de sociedades. Em referido estudo, que foi elaborado por um grupo de pesquisadores, desenvolveu-se uma análise do texto legal buscando-se o estatuto semiológico do discurso jurídico tomado no seu conjunto. Diferenciaram-se discurso legislativo e discurso referencial, notando-se que o texto jurídico possui dupla isotopia, a primeira representada pelo discurso legislativo, e a segunda pelo discurso referencial. Partiu-se, então para a especificação do discurso jurídico em relação à língua natural em que se manifesta, o que levou os pesquisadores a identificar uma gramática e manifestação de um universo semântico particular, derivando-se daí uma gramática jurídica e uma gramática narrativa. 
Ao tratar da diferenciação entre discurso legislativo, discurso referencial e língua natural, assim como das características do discurso jurídico Greimas esclarece:

De fato, é realmente o discurso legislativo que, selecionando os elementos referenciais na língua natural, confere-lhes o estatuto de nível referencial e, operando seu fechamento em relação às significações circundantes, integra-os no discurso jurídico; por conseguinte, na ordem do ser semiótico, o nível legislativo em direito é anterior e se acha pressuposto no nível referencial. Como vimos, a língua natural é um sistema semiótico complexo, pelo fato de permitir no seu interior o desenvolvimento de metassemióticas segundas, como a linguagem jurídica, cuja manifestação discursiva temos que analisar. Um novo conceito de conotação é constituído pelo conjunto de significados secundários que, além de seu sentido denotativo e abertamente intencional, todo texto engendrado por um sistema semiótico qualquer pode comportar. (GREIMAS, 1981, p. 74-75).

O respeito da isotopia referencial do discurso o autor esclarece o efeito de ilusão que o discurso legislativo exerce sobre as pessoas, como se apenas descrevesse e organizasse os fatos da natureza em termos legislativos. Escreve o autor:

Ocorre provavelmente o mesmo com o sentimento de "realidade" da isotopia referencial do discurso: esta impõe-se ao leitor como um verossímil social, mais que isso, como um a priori lógico que a fala legislativa apenas descreve e organiza. Esta ilusão de realidade recobre de outra maneira a totalidade do discurso jurídico, conferindo às denominações e às definições jurídicas (sociedade, conselho de administração, assembleia etc.) o estatuto de objetos semióticos autônomos, dotados de personalidade, de funções quase orgânicas etc., em outras palavras, transformando objetos discursivos, fatos de fala, em objetos semióticos, organismos e instituições. A conotação social pode não passar de um conjunto de efeitos de sentido; nem por isso ela deixa de constituir uma dimensão simbólica autônoma que dá conta do peso dos discursos jurídicos e da credibilidade das instituições do direito (GREIMAS, 1981, p. 75).

Para produzir esse efeito o direito conta com diversos mecanismos que lhe conferem o atributo de juridicidade, que fazem com que independentemente do se enuncie ou veicule, os textos jurídicos apresentem, além da dimensão denotativa, também uma dimensão conotativa marcada pela ambiguidade, incompreensão, ameaças implícitas etc.. Além desses mecanismos, o discurso jurídico também apresenta uma gramática jurídica distinta da gramática da língua natural, podendo-se conceber, ainda, um dicionário jurídico autônomo. Essas regras criam um universo semântico que o autor denomina universo jurídico. A hipótese trabalhada pelo autor é que: "o texto a ser descrito [a lei sobre sociedades comerciais] pertence a uma semiótica jurídica, que ele e o produto de uma gramática e manifestação de um universo semântico particular" (GREIMAS, 1981, p. 76).

Ao tratar do método de análise o autor propõe: 
[...] os processos jurídicos, embora obedeçam às regras da gramática jurídica no sentido estrito, estão ao mesmo tempo ligadas à gramática narrativa; por conseguinte, seu estudo exige uma metodologia apropriada. Uma hipótese de trabalho: o reconhecimento das propriedades narrativas de certas sequencias do discurso jurídico autoriza a utilizar os modelos narrativos gerais para dar conta da organização de certos discursos jurídicos, mais particularmente daqueles que se referem às sociedades comerciais e aos grupos de sociedades (GREIMAS, 1981, p. 84).

Esboçado o modelo teórico, passou-se a trabalhar com os actantes, sujeitos coletivos, e funções do ser, saber, fazer, querer e poder, aplicando-se teorias e chaves teóricas semióticas à análise do texto da lei.

Referido estudo mostra as contribuições que a análise semiótica pode proporcionar à compreensão de textos jurídicos. A depender da abordagem pode-se ampliar o escopo semiótico para compreender também conflitos de classes, o que se supõe seja possível com o manejo dos conceitos e teorias desenvolvidos por Volóchinov (2018), ou outros autores que também desenvolvam pesquisas em tal dimensão.

Tais investigações exigem a especificação do objeto, de tal forma que se torne possível identificá-lo em seus caracteres duradouros ou regulares ou relacionais, diferenciá-lo de outros objetos, e de então em diante elaborar descrições, classificações, análises e demais formas de conhecimentos que tornam possíveis elaborações de teorias, modelos explicativos, modelos teóricos sistêmicos ou processuais, leis, enfim, formas de conhecimentos que podem ser qualificados por sua forma de construção, métodos, técnicas, objetos.

Sendo a semiótica uma das áreas da ciência, utiliza linguagem e metalinguagem. Orlandi explica: “Toda ciência tem de ter uma metalinguagem, pela qual estabelece suas definições, conceitos, objetos e procedimentos de análise" (ORLANDI, 2009, p. 16).

No caso da semiótica, quando toma o direito por linguagem objeto, apresenta-se como metalinguagem. Daí a necessidade de compreensão dos conceitos, teorias e modelos explicativos da semiótica, situando-os na tradição dos estudos clássicos ou mais modernos, o que torna possível identificar quais as chaves e referências teóricas, qual o modelo teórico adotado, o que balizará as perguntas a serem feitas na investigação com repercussão nas respostas.

Quando se refere a semiótica jurídica não se está referido a uma teoria ou modelo teórico diferente daqueles existentes na semiótica. Trata-se apenas da utilização da semiótica como metateoria e metalinguagem. O direito, neste caso, figura como linguagem-objeto. 
No verbete "semiótica" elaborado por Araújo, na Enciclopédia jurídica da Pontifícia Universidade Católica de São Paulo há uma excelente apresentação das abordagens que costumam ser adotadas por quem se propõe a estudar semiótica no âmbito jurídico.

\section{CONCLUSÃO}

Pesquisadores, investigadores e estudiosos que pretendam estabelecer esse diálogo teórico entre semiótica e direito precisam conhecer, compreender e saber utiliar conceitos e teorias semióticos com vistas à propositura de perguntas e obtenção de respostas nessa análise que toma o direito por linguagem objeto.

Sendo o direito e a semiótica universos teóricos bastante vastos e complexos, e objetos de investigação também bastante complexos, vastos e variados, exigem delimitação e rigor quando da escolha do objeto e método de investigação. Pretender que apenas um autor, modelo ou referencial teórico expresse a totalidade do que seja semiótica mostra-se uma postura ingênua.

No presente trabalho esperamos ter demonstrado que são várias as teorias semióticas, os autores e referenciais teóricos, o que exige identificação e especificação quando da apresentação dos argumentos e fundamentos da investigação. Não é suficiente reconhecer o direito como um sistema de signos. É preciso especificar qual tipo de signo, se se apresenta dicotomicamente como em Saussure ou tricotomicamente como em Peirce, qual a dimensão investigada, apenas para retomar a teoria de Morris que relaciona sintaxe, semântica e pragmática, o que pode aproiximar as investigações mais dos modelos lógico-matematizados, como se dá no positivismo lógico, semânticos como apresenttado por Benveniste, ou dos modelos dialógicos, como se dá em Bakhtin?

Trata-se de vasto campo de investigação, que muito pode contribuir para a compreensão do direito, somando-se às teorias jurídicas existentes. 


\section{REFERÊNCIAS}

ARAÚJO, C. V. O. D. Semiótica jurídica. In: CAMPILONGO, C. F.; GONZAGA, A. D. A. G.; FREIRE, A. L. Enciclopédia Jurídica da PUC-SP: Tomo: Teoria Geral e Filosofia do Direito. São Paulo: Pontifícia Universidade Católica de São Paulo, 2017. Disponivel em: <https://enciclopediajuridica.pucsp.br/verbete/96/edicao-1/semioticajuridica>. Acesso em: 11 abr. 2021.

BARROS, D. L. P. D. Teoria semiótica do texto. São Paulo: Parma, 2005.

BENVENiste, É. Problemas de linguística geral II. Tradução de Eduardo Guimarães. Campinas: Pontes, 1989.

ECO, U. Tratado geral de semiótica. Tradução de Antônio de Pádua Danesi e Gilson Cesar Cardoso de Souza. São Paulo: Perspectiva, 2009.

GREIMAS, A. J. Semiótica e ciências sociais. Tradução de Álvaro Lorencini e Sandra Nitrini. São Paulo: Cultrix, 1981.

GREIMAS, A. J.; COURTÉS, J. Dicionário de semiótica. Tradução de Alceu Dias Lima; Diana Luz Pessoa de Barros, et al. São Paulo: Cultrix, 2008.

JAKOBSON, R. Linguística e comunicação. Tradução de Izidoro Blikstein e José Paulo Paes. 22. ed. São Paulo: Cultrix, 2010.

KLINKENBERG, J. M. Manual de semiótica general. Bogotá: Fundación Universidad de Bogotá Jorge Tadeo Lozano, 2006.

KRISTEVA, J. Semiótica 1. 2. ed. Madrid: Espiral Editorial Fundamentos, v. 1, 1981.

LOTMAN, I. M. La semiosfera: semiótica de la cultura y del texto. Madrid: Ediciones Cátedra S. A., v. I, 1996.

MORRIS, C. W. Fundamentos da teoria dos signos. Tradução de Paulo Alcoforado e Milton José Pinto. São Paulo: Ed. da Universidade de São Paulo, 1976.

NÖTH, W. Panorama da semiótica de Platão a Peirce. 4. ed. São Paulo: Annablume, 1995.

NÖTH, W.; SANTAELLA, L. Introdução à semiótica: passo a passo para compreender os signos e a significação. São Paulo: Paulus, 2017.

ORLANDI, E. P. O que é linguística. São Paulo: Brasiliense, 2009. 
PEIRCE, C. S. Semiótica. Tradução de José Teixeira Coelho Neto. São Paulo: Perspectiva, 2008.

SAUSSURE, F. D. Curso de lingüística geral. Tradução de Antônio Chelini; José Paulo Paes e Izidoro Blikstein. 27. ed. São Paulo: Cultrix, 2006.

VOLÓCHINOV, V. Marxismo e filosofia da linguagem: problemas fundamentais do método sociológico na ciência da linguagem. Tradução de Sheila Grillo e Ekaterina Vólkova Américo. 2. ed. São Paulo: 34, 2018. 